\title{
Job demands-resources model in the context of recovery: Testing recovery experiences as mediators
}

\author{
Ulla Kinnunen \\ Department of Psychology, University of Tampere, Tampere, Finland \\ Taru Feldt \\ Department of Psychology, University of Jyväskylä, Jyväskylä, Finland \\ Marjo Siltaloppi \\ Department of Psychology, University of Tampere, Tampere, Finland \\ Sabine Sonnentag \\ Department of Psychology, University of Konstanz, Konstanz, Germany
}

\begin{abstract}
The aim of the present study was to extend the original Job DemandsResources (JD-R) model by taking into account recovery as an important mediation mechanism between work characteristics and well-being/ill-health. Specifically, we examined whether recovery experiences - strategies promoting recovery-might have a mediating role in the JD-R model among 527 employees from a variety of different jobs. The results showed that psychological detachment fully mediated the effects of job demands on fatigue at work and mastery partially mediated the effects of job resources on work engagement. Altogether, the results suggest that recovery merits consideration as a mediating mechanism in the JD-R model.
\end{abstract}

Keywords: Fatigue; Job demands; Job Demands-Resources model; Job resources; Recovery experiences; Work engagement.

The Job Demands-Resources (JD-R) model attempts to explain both the well-being and ill-health of employees by psychosocial work characteristics

Correspondence should be addressed to Ulla Kinnunen, Department of Psychology, 33014 University of Tampere, Tampere, Finland. E-mail: ulla.kinnunen@uta.fi

The research project "The Role of Recovery from Job Strain in Maintaining Occupational Well-being" was financially supported by The Finnish Work Environment Fund (Grant No. 106046).

(c) 2011 Psychology Press, an imprint of the Taylor \& Francis Group, an Informa business http://www.psypress.com/ejwop

http://dx.doi.org/10.1080/1359432X.2010.524411 
(Demerouti, Bakker, Nachreiner, \& Schaufeli, 2001; Schaufeli \& Bakker, 2004). In the present study we tested the basic assumptions of the JD-R model in the context of recovery, that is, we focused on the main effects of work characteristics on well-being and ill-health. We considered recovery an important mediation mechanism between work characteristics and wellbeing/ill-health, as it has been argued that lack of recovery (e.g., stressrelated physiology) plays a crucial mediation role in explaining why job stressors may produce poor well-being and health problems (e.g., Demerouti, Bakker, Geurts, \& Taris, 2009; Geurts \& Sonnentag, 2006).

Recovery has been defined in several ways (see, e.g., Demerouti et al., 2009). Generally speaking, recovery refers to the process during which an individual's functioning returns to its prestressor level and in which strain is reduced (Craig \& Cooper, 1992). It has also been defined as a process that allows individuals to replenish their resources (Meijman \& Mulder, 1998; Trougakos \& Hideg, 2009). When recovery is insufficient, an individual has to put in some extra effort at work to get through normal tasks, which may inflict strain and in the long run lead to health deterioration and sickness absence (Meijman \& Mulder, 1998).

In our study, we focus on recovery experiences, which are strategies that have the potential to promote recovery (Sonnentag \& Fritz, 2007). Recovery experiences refer to the degree to which the individual perceives that the activities of nonwork time help him/her to restore energy resources. Specifically, we examine, whether recovery experiences have a mediating role in the work characteristics-well-being/ill-health relationship. Thus, our aim is to extend the JD-R model in the direction of examining recovery strategies as mediating mechanisms. This is one of the avenues for future research called for by Bakker and Demerouti (2007) in the context of the JD-R model (see, e.g., Xanthopoulou, Bakker, Demerouti, \& Schaufeli, 2007, for the meditation role of self-efficacy, self-esteem, and optimism).

The original JD-R model does not take into account personal factors like resources, which are - besides work characteristics - important in determining work-related well-being (e.g., Mäkikangas \& Kinnunen, 2003; Xanthopoulou et al., 2007). Personal resources refer to individuals' sense of their ability to control and impact upon their environment successfully (Hobfoll, Johnson, Ennis, \& Jackson, 2003). Recovery experiences can be considered as processes that protect and foster such personal resources, as they have the potential to attenuate the threats related to well-being and the associated physiological and psychological costs. Although there is some evidence showing recovery experiences to work as moderators in the stressoroutcome relationships (e.g., Moreno-Jimenez et al., 2009; Siltaloppi, Kinnunen, \& Feldt, 2009), their mediation role has not received attention thus far, with one exception. Sonnentag, Kuttler, and Fritz (2010) recently showed that psychological detachment was a partial mediator between job stressors and strain reactions among a sample of protestant pastors. 


\section{THE JD-R MODEL}

The first basic assumption of the JD-R model is that, regardless of the type of job, psychosocial work characteristics can be categorized into two groups: job resources and job demands (Bakker \& Demerouti, 2007; Demerouti et al., 2001; Schaufeli \& Bakker, 2004). Job demands refer to those aspects of a job that require sustained physical and/or psychological effort and are therefore associated with certain physiological and/or psychological costs. According to Bakker and Demerouti (2007), job demands are not necessarily negative; they may turn into negative job stressors when meeting those demands requires major effort from which the employee has not adequately recovered (Meijman \& Mulder, 1998).

Job resources refer to those aspects of a job that are functional in achieving work goals, may reduce job demands and the associated physiological and psychological costs, and stimulate personal growth, learning, and development. Job resources may foster either extrinsic or intrinsic motivation at work. The former occurs because resources are necessary to cope with job demands and to achieve work goals. The latter relates to the fact that by satisfying the basic psychological needs of autonomy, belongingness, and competence, job resources are also intrinsically motivating for employees (van den Broeck, Vansteenkiste, de Witte, \& Lens, 2008).

According to the second basic assumption of the JD-R model, two different underlying processes - the health impairment process and the motivational process - play a role in the development of ill-health and wellbeing (Bakker \& Demerouti, 2007). In the health impairment process, chronic job demands exhaust employees' mental and physical resources and may therefore lead to the depletion of energy. As a result, job demands are related to strain, including development of fatigue, burnout, and health problems. In the motivational process, job resources are related to motivation, including engagement with and commitment to work.

In the present study, we focused on two outcomes, namely fatigue at work and work engagement, representing respectively the health impairment and motivational processes in the JD-R model. Fatigue at work was approached by two concepts: need for recovery and job exhaustion. First, need for recovery is the sense of urgency that people feel to take a break from their demands, when fatigue builds up (Sluiter, van der Beek, \& Frings-Dresen, 1999; van Veldhoven \& Broersen, 2003). Inherent in the experience is a temporary reluctance to continue with the present demands or even accept new demands. Need for recovery from work can, therefore, be viewed as an early stage of a long-term strain process leading to prolonged fatigue, distress, and cardiovascular symptoms (Jansen, Kant, \& van den Brandt, 2002). Second, job exhaustion is the core symptom of burnout (Maslach, Schaufeli, \& Leiter, 2001). It refers to feelings of 


\section{KINNUNEN ET AL.}

overstrain, tiredness, and fatigue resulting from long-term involvement in an overdemanding work situation depleting an individual's overall energy. The state of exhaustion is chronic and not relieved by daily or weekly rest (Maslach et al., 2001; Schaufeli \& Enzmann, 1998). Consequently, job exhaustion can be considered a more serious sign of the long-term strain process than need for recovery; however, fatigue is a shared symptom in both concepts.

Work engagement is defined as a positive, fulfilling, work-related state of mind that is characterized by vigour, dedication, and absorption (Bakker, Schaufeli, Leiter, \& Taris, 2008; Schaufeli, Salanova, González-Romá, \& Bakker, 2002). Vigour refers to high levels of energy and mental resilience while working, the willingness to invest effort in one's work, and persistence in the face of difficulties. Dedication is perceived as a sense of significance, enthusiasm, inspiration, pride, and challenge at work. Absorption is characterized by being fully concentrated and happily engrossed in one's work, whereby time passes quickly and one has difficulties in detaching oneself from work.

Several studies have provided evidence for the idea that job demands and resources are responsible for the two different processes (see Bakker \& Demerouti, 2007, for a review). First, both previous cross-sectional and longitudinal studies have identified positive associations between job demands and dimensions of burnout (e.g., Hakanen, Schaufeli, \& Ahola, 2008; Schaufeli, Taris, \& van Rhenen, 2008; for reviews, see Halbesleben \& Buckley, 2004; Schaufeli \& Enzmann, 1998). Second, a positive relationship between job resources and work engagement has been found in several cross-sectional (e.g., Bakker, Hakanen, Demerouti, \& Xanthopoulou, 2007; Hakanen, Bakker, \& Schaufeli, 2006; Schaufeli \& Bakker, 2004) and in a few longitudinal studies (Hakanen et al., 2008; Mauno, Kinnunen, \& Ruokolainen, 2007).

There is also evidence showing intertwining effects between the motivational and health impairment processes. In line with the third basic assumption of the JD-R model, lack of resources (e.g., lack of job control and social support) has been linked to fatigue and burnout in both crosssectional and longitudinal studies (e.g., Hakanen et al., 2008; Schaufeli \& Bakker, 2004; see Lee \& Ashforth, 1996, for a review). Although the JD-R model (Schaufeli \& Bakker, 2004) does not hypothesize any relationship between job demands and engagement, there are studies reporting either a negative or positive relationship. First, a negative relationship - although not strong - emerged in the longitudinal studies by Hakanen et al. (2008) and Mauno et al. (2007): High job demands were related to low work engagement over time. Second, high job demands (e.g., work pressure) were positively related to each work engagement scale in the study by Schaufeli and colleagues (2008) among managers. In addition, there are studies in 
which long working hours have been linked to high work engagement (e.g., Kinnunen, Feldt, \& Mäkikangas, 2008). However, according to a recent meta-analysis, job demands (across 111 unique samples) have been related to work engagement more often negatively than positively (Halbesleben, 2010). Altogether, the role of job demands in relation to work engagement seems not to be fully established likely due to the fact that job demands are not necessarily negative job stressors (Bakker \& Demerouti, 2007).

\section{RECOVERY EXPERIENCES AND WELL-BEING/ ILL-HEALTH}

In the present study, we focused on the mechanisms helping recovery, which are called recovery experiences by Sonnentag and Fritz (2007). They have proposed four such mechanisms; psychological detachment from work, relaxation, mastery, and control during leisure time. These mechanisms can be seen as personal strategies by which individuals try to restore their energy resources and maintain well-being despite stressful situations.

Psychological detachment and relaxation have their roots in the EffortRecovery (E-R) model (Meijman \& Mulder, 1998), and mastery and control in the Conservation of Resources (COR) theory (Hobfoll, 1998). According to the E-R model, effort at work leads to load reactions (e.g., excretion of stress hormones, feelings of fatigue), and when an individual is no longer confronted with work demands, load reactions are released and recovery occurs. Therefore, psychological detachment and relaxation may be helpful, because they imply that no further demands are made on the functional systems (e.g., neuroendocrine and cardiovascular systems) and internal resources (e.g., self-regulation) called upon during work. On the basis of the COR theory, stress occurs when an individual's valued resources (e.g., energy) are threatened or lost or when no resources are gained after resource investment. Thus, to recover from stress an individual has to gain new resources or restore threatened or lost resources. Consequently, masteryoriented strategies - mastery and control-may aid recovery because they build up resources such as energy or feelings of control, which help to restore threatened resources.

Psychological detachment implies disengaging mentally from work during off-job time (Sonnentag \& Fritz, 2007). This means more than just being away from work physically; thus, an individual also needs to stop thinking about his or her job and job-related affairs. In everyday terms, psychological detachment is often experienced as "switching off" during off-job time (Sonnentag \& Bayer, 2005). Empirical evidence suggests that psychological detachment is helpful in recovering from job strain. First, Sonnentag and Fritz (2007) showed that psychological detachment was negatively related to health complaints, emotional exhaustion, depressive symptoms, need for 
recovery, and sleep problems. Second, several diary studies suggest that individuals who experienced psychological detachment from work during leisure time reported better mood and less fatigue in the evening at bedtime and next morning (Sonnentag \& Bayer, 2005; Sonnentag, Binnewies, \& Mojza, 2008). It has also been shown that a balance between high engagement at work and high disengagement from work during nonwork time is highly relevant for protecting employees' well-being (Sonnentag, Mojza, Binnewies, \& Scholl, 2008).

Relaxation is a state characterized by a low activation (decreased sympathetic activation) and increased positive affect (Sonnentag \& Fritz, 2007). This state may be either a result of deliberately chosen strategies aiming at the relaxation of body and mind, like meditation or progressive muscle relaxation, or relaxation may occur less deliberately, for example, by reading a book, taking a walk, or listening to music. In the study by Sonnentag and Fritz (2007), relaxation was negatively related to health problems, emotional exhaustion, need for recovery, and sleep problems. Further, the one-week diary study by Sonnentag, Binnewies, and Mojza (2008) showed that relaxation in the evening had a positive effect on mood next morning.

The mastery experience refers to pursuing mastery-related off-job activities (e.g., taking a language class or learning new sports) that offer an individual challenges or opportunities to learn new skills (Fritz \& Sonnentag, 2006; Sonnentag \& Fritz, 2007). Although mastery experiences may impose extra demands on the individual, these experiences are expected to enhance recovery because they help to build up new internal resources, such as skills, competencies, self-efficacy, and positive mood (see Sonnentag \& Fritz, 2007, for more details). Mastery experiences also seem to be related to recovery. First, Sonnentag and Fritz (2007) showed that mastery was negatively related to emotional exhaustion, depressive symptoms, and need for recovery. Second, additional studies have demonstrated that higher levels of mastery experiences during a vacation were related to lower levels of exhaustion on the employee's return to work (Fritz \& Sonnentag, 2006), and that mastery in the evening was related to morning positive affect (Sonnentag, Binnewies, \& Mojza, 2008).

Control applied to leisure time refers to control over such decisions as which activity to pursue, when and how to pursue this chosen activity. According to Sonnentag and Fritz (2007), the experience of control during leisure time may increase self-efficacy and feelings of competence; therefore, it may be an external resource that promotes recovery from job strain and well-being. In general, individual well-being is increased when one feels in control of important life domains (Bandura, 1997). Sonnentag and Fritz (2007) found that control was negatively related to health complaints, emotional exhaustion, depressive symptoms, need for recovery, and sleep problems, and positively related to life satisfaction. 


\section{JOB DEMANDS AND RESOURCES AND RECOVERY EXPERIENCES}

Job demands can be seen as factors that inhibit recovery, whereas job resources facilitate recovery (see Demerouti et al., 2009). The inhibiting role of job demands on recovery has been shown in several studies. For example, high job demands have been related to high need for recovery in crosssectional (Jansen, Kant, van Amelsvoort, Nijhuis, \& van den Brandt, 2003), longitudinal (de Croon, Sluiter, Blonk, Broersen, \& Frings-Dresen, 2004; de Raeve, Vasse, Jansen, van der Brandt, \& Kant, 2007), and diary (Sonnentag \& Zijlstra, 2006) studies. The facilitating role of job resources is well illustrated by Rau (2006), who indicated that learning opportunities at work (e.g., decision authority, responsibility, feedback) were positively associated with nocturnal recovery of heart rate and blood pressure. Also, from the diary study by Sonnentag and Zijlstra (2006) it emerged that job control was negatively related to need for recovery at bedtime. In addition, longitudinal studies (de Croon et al., 2004; de Raeve et al., 2007) have confirmed that an increase in job control predicted a subsequent decrease in need for recovery.

However, less is known about the role of job demands and resources in relation to specific recovery experiences. The only comprehensive study conducted so far, by Sonnentag and Fritz (2007), showed that all job demands examined (i.e., time pressure, role ambiguity, situational constraints, hours of overtime) were negatively related to detachment and control during leisure time. In addition, time pressure inhibited relaxation. However, none of the job demands were significantly related to mastery experiences. The only job resource examined was job control, which was positively associated only with control during leisure time. In another longitudinal study, Grebner, Semmer, and Elfering (2005) showed that high job control was related to inability to switch off after work. Further evidence concerning the relationships comes from the study by Sonnentag and Bayer (2005), which showed that high demands on a specific day increased the risk of not being able to detach from work, and from the study by Rau (2006), which also indicated that job demands were related to impaired ability to relax at home.

\section{THE PRESENT STUDY: THE MEDIATION HYPOTHESES OF RECOVERY EXPERIENCES}

Altogether, we tested the extended JD-R model, shown in Figure 1, which we labelled Job Demands-Resources-Recovery (JD-R-R) model. In the model, in line with the basic assumptions of the JD-R model, job demands are likely to inhibit recovery and therefore promote the process impairing health (i.e., fatigue), whereas job resources facilitate recovery and maintain 


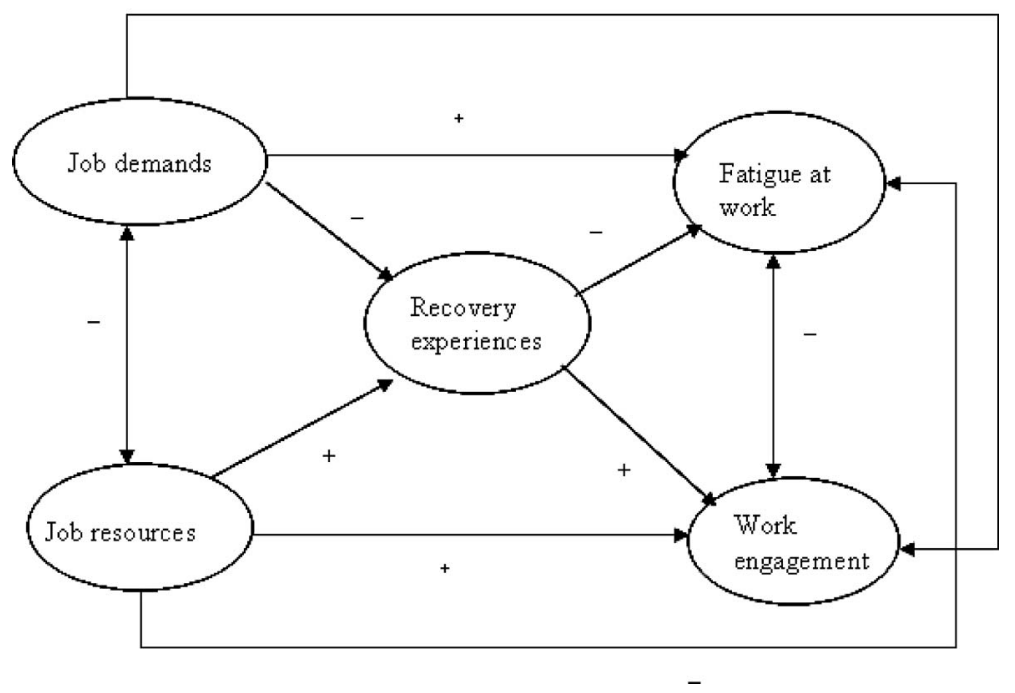

Figure 1. The theoretical Job Demands-Resources-Recovery (JD-R-R) model tested in the study.

the motivational process (i.e., work engagement). Of the specific recovery experiences potentially mediating these relationships, our line of reasoning was based on the JD-R model and the recovery literature and theories (E-R model, COR theory) reviewed earlier.

However, because the Recovery Experience Questionnaire (REQ; Sonnentag \& Fritz, 2007) is a new tool and has not been used before in a Finnish context, we do not have knowledge about its psychometric properties. Therefore, as a prerequisite for sound further analyses the construct validity of the Finnish Recovery Experience Questionnaire is first examined on the basis of the following hypothesis.

Hypothesis 1: The Finnish REQ has four dimensions, which are psychological detachment, relaxation, mastery, and control.

In line with the health impairment process, job demands were expected to challenge especially psychological detachment and relaxation during nonwork time. Poor detachment and relaxation, in turn, were expected to be linked to increased fatigue. We based this view on the fact that exposure to high job demands (e.g., high work load) may increase the risk that a person ruminates about his or her work after the working day is over (see Cropley $\&$ Purvis, 2003), which means that he or she has difficulties in psychological 
detachment from work. As a consequence, he or she may also have problems in relaxation due to the prolonged activation and negative affect related to work. Finally, these processes - rumination, prolonged activation, and negative affect - tax the same systems activated on the job and so maintain fatigue in line with the E-R model (Meijman \& Mulder, 1998).

It is also possible that job demands are linked to decreased mastery experiences and control during nonwork time. As job demands exhaust employees' mental and physical resources (Bakker \& Demerouti, 2007), employees may not have enough effort left for mastery experiences, that is, to address new challenges or learn new things during leisure time. In the same way, high job demands may increase the feeling of being out of control during nonwork time, for example, by decreasing leisure time or by being cognitively occupied with work affairs. Consequently, the employees' resources (e.g., self-esteem, competence, mood) may not be restored through mastery and control, which is reflected in elevated levels of fatigue.

On the basis of the JD-R model and the strong evidence supporting the main effect of job demands on fatigue at work, we also expect a direct link between job demands and fatigue at work. Consequently, our mediation hypothesis is only partial. In addition, the partial mediation - as opposed to full meditation - may be expected as job demands might also increase fatigue at work by other mechanisms (e.g., depleting resources during the working day) than recovery experiences during nonwork time (Sonnentag et al., 2010).

We formulate the following hypothesis concerning the mediation role of recovery experiences in the health impairment process:

Hypothesis 2: Recovery experiences - especially psychological detachment and relaxation - partially mediate the relationship between job demands and fatigue at work.

Consistent with the motivational process, job resources are expected to promote especially mastery experiences and control during nonwork time, and these two recovery experiences, in turn, are proposed to promote work engagement signalling adequate recovery. The line of reasoning behind this mediation hypothesis is based on the COR theory (Hobfoll, 1998). According to the theory, individuals with a strong resource pool will invest their resources in order to improve their condition and obtain new resources. Thus, resources tend to accumulate and generate other resources. Adapted to the present study, employees who have high resources on the job are likely to have more internal resources (e.g., energy, self-efficacy) available for learning and decision making during nonwork time. As a result, they may spend their leisure time in gaining mastery experiences or perceive having higher control over leisure time (see Sonnentag \& Fritz, 
2007). These experiences in turn help-via restoring or creating such resources as self-efficacy - recover and maintain motivation in the form of work engagement.

Contrary to job demands, it is possible that job resources promote psychological detachment and relaxation during nonwork time as high job resources (e.g., social support) may decrease the risk that a person ruminates or has negative affect towards his or her job after work. However, it may also be possible that high job resources increase the person's positive thoughts about his or her job during leisure time. In this case, although the person may not be detached from his or her work during leisure time, his or her recovery may not suffer as positively reflecting about one's work mayas a resource-providing experience (Binnewies, Sonnentag, \& Mojza, 2009) - even improve well-being (Fritz \& Sonnentag, 2005). If the level of work-related positive affect is high, it may also hinder relaxation to some extent through a high activation level, but in the case of positive activated affect lack of relaxation may not be so detrimental to well-being, either. As a consequence, we can expect a less uniform relation between job resources on the one hand and psychological detachment and relaxation on the other hand. Again, as the main effect of job resources on work engagement has received robust support and as there are also other mechanisms (e.g., positive self-evaluations; Xanthopoulou et al., 2007) mediating the effects of job resources and work engagement, we expected the direct link, suggesting partial mediation.

For the mediation role of recovery experiences in the motivational process, we hypothesize:

Hypothesis 3: Recovery experiences - especially mastery and controlpartially mediate the relationship between job resources and work engagement.

Finally, for the intertwining effects between the health impairment and motivational processes, we make two additional hypotheses:

Hypothesis 4: Job resources have a negative link to fatigue at work.

Hypothesis 5: Job demands have a negative link to work engagement.

\section{METHODS}

\section{Participants and procedure}

The original sample $(N=1042)$ comprised employees of five Finnish organizations from various sectors such as business, the telecommunications 
and information technology, hotel and catering, travel services, and education. By sampling different organizations we wanted to include employees from a variety of different jobs. All the participating organizations were located in a city with about 200,000 inhabitants, and they were recruited from the client organizations of one local company supplying occupational health services. So, the sample is a convenience sample. The data collection was performed in spring (March-June) 2007, using a 12-page questionnaire distributed to each employee at his or her workplace. The completed questionnaires were returned in sealed envelopes to the researchers by mail. Of the employees contacted, 527 returned the completed questionnaire after a reminder, yielding a response rate of $51 \%$.

Of the participants, $53 \%$ were women. Participants' mean age was 42.4 $(S D=11.7)$. Most participants $(77 \%)$ were living with a partner (either married or cohabiting), and $43 \%$ had children (average of two) living at home. The majority $(60 \%)$ had an academic degree, $21 \%$ had a higher vocational qualification, and the rest $(19 \%)$ had a vocational school qualification or less. Of the participants, $53 \%$ worked in the public sector as teachers and researchers, and $47 \%$ worked in the private sector in hotels $(17 \%)$, in an information technology company $(11 \%)$, in travel services $(9 \%)$, and in hardware stores $(10 \%)$. Most participants had a permanent employment contract $(68 \%)$ and worked full time $(87 \%)$. Mean working hours per week were 43.3 hours $(S D=9.9)$.

\section{Measures}

Job demands. As job demands we examined time demands, demands in decision making, and weekly working hours, which all belong to job demands on the basis of the definition and categorization presented by Bakker and Demerouti (2007). Time demands and demands in decision making were measured with the QPSNordic Questionnaire developed and validated by Lindström et al. (2000). Time demands were assessed with four items (e.g., "Does your job require you to work fast?") and demands in decision making with three items (e.g., "Does your job require you to make complicated decisions?"). The items were scored on a 5-point rating scale ranging from 1 ("very seldom or never") to 5 ("very often or always"). The Cronbach's alphas were .78 for time demands, and .63 for demands in decision making. In addition, weekly working hours (including all duties) were asked by a single question.

Job resources. As job resources we focused on job control, social support from colleagues, and justice of the supervisor. They have been categorized into job resources by Bakker and Demerouti (2007). All the job 
resources were also assessed with the QPSNordic Questionnaire (Lindström et al., 2000). Job control included four items (e.g., "Can you influence your workload?"; Cronbach's alpha $=.73$ ), social support included two items (e.g., "Do your colleagues provide help and support when needed?"; Cronbach's alpha $=.84)$, and justice of the supervisor included three items (e.g., "Does your immediate supervisor treat employees fairly and impartially"; Cronbach's alpha $=.83$ ). The items were scored on a 5-point rating scale ranging from 1 ("very seldom or never") to 5 ("very often or always").

Recovery experiences. The participants completed the 16-item Recovery Experience Questionnaire (REQ; Sonnentag \& Fritz, 2007), assessing their recovery experiences with respect to their free time after work on a 5-point scale ranging from 1 ("totally agree") to 5 ("totally disagree"). The REQ was first translated from English to Finnish, and after that a Finnish-English linguistic professional checked the cross-cultural accuracy of the translation and backtranslated it into English. Four items per scale measured each experience: psychological detachment (e.g., "I don't think about work at all"), relaxation (e.g. "I use the time to relax"), mastery (e.g., "I do things that challenge me"), and control (e.g., "I feel like I can decide for myself what to do"). The items were recoded so that a high score on each scale indicated a high level of the experience studied. Internal consistency (Cronbach's alpha) was .89 for psychological detachment, .82 for relaxation, .83 for mastery, and .85 for control.

Occupational well-being. From the perspective of health impairment, we measured fatigue at work by three indicators. First, for assessing the shortterm effects of a day at work we measured need for recovery by nine items from the Need for Recovery Scale (van Veldhoven \& Broersen, 2003). All the items we used focus on the time after the working day (e.g., "Generally, I need more than an hour before I feel completely recuperated after work") and they were rated on a 4-point scale from 1 ("never") to 4 ("always"). High scores reflect high levels of need for recovery. The Cronbach's alpha of the scale was .89. Second, we asked with a single question about an individual's own evaluation of his or her recovery "How well do you generally feel to recover from the strain caused by your job after the working day?" (from $1=$ "very well" to $5=$ "very poorly"). This single-item measure has proved to behave in a similar way as job exhaustion and need for recovery, that is, yield similar patterns of correlations with potential antecedents and consequences (see Table 1). Third, job exhaustion was measured using the 5-item exhaustion scale of the Maslach Burnout Inventory-General Survey (Maslach, Jackson, \& Leiter, 1996), which has been validated in Finland (Kalimo, Hakanen, \& Toppinen-Tanner, 2006). 


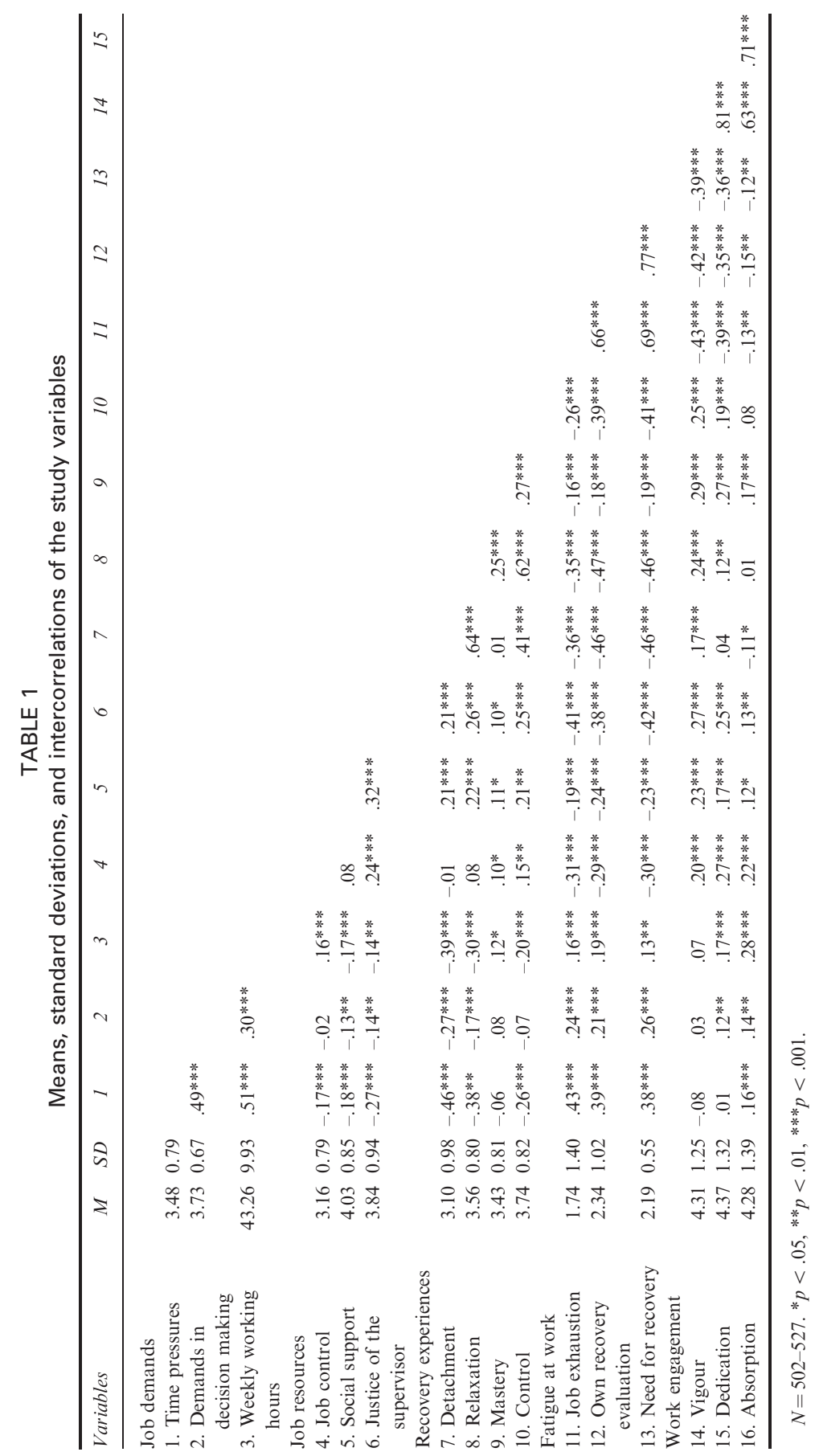


The items (e.g., "I feel emotionally drained from my work") were scored on a 7-point rating scale ranging from 0 ("never") to 6 ("daily"). The Cronbach's alpha of the job exhaustion scale was .93.

From the motivational perspective, we measured work engagement by the shortened scales of vigour, dedication, and absorption with the 9-item Utrecht Work Engagement Scale (Schaufeli, Bakker, \& Salanova, 2006), of which construct validity has been found to be good in Finnish occupational samples (Seppälä et al., 2009). Each scale included three items: e.g., "At my work, I feel bursting with energy" (vigour; Cronbach's alpha =.88), "I am enthusiastic about my work" (dedication; Cronbach's alpha $=.89$ ), and "I get carried away when I am working" (absorption; Cronbach's alpha $=.83$ ). The items were rated on a 7-point scale ranging from 0 ("never") to 6 ("daily").

Table 1 displays means, standard deviations, and correlations for all study variables.

\section{RESULTS}

\section{The construct validity of the Finnish REQ}

In order to be sure that the Finnish REQ had a four-factor structure (i.e., psychological detachment, relaxation, mastery, and control during leisure time), we computed a series of confirmatory factor analyses (CFAs) using Mplus 5.2 program (Muthén \& Muthén, 1998-2007). For the CFAs, the missing values were handled with the missing data method, which utilizes all the available data (i.e., the standard missing at random approach). As not all the items of the scale were fully normally distributed, we used maximum likelihood estimator with robust standard errors (MLR) and $\chi^{2}$ as the method of estimation.

Altogether, we tested a hypothesized four-factor model (Model 1) and four alternative models, which proved to be the statistically best fitting models in the Sonnentag and Fritz' (2007) CFA analyses, in order to ensure that the hypothesized model was valid. The alternative models were a one-factor model where all items were defined to the same factor (Model 2), a two-factor model containing the items of psychological detachment and relaxation in the first factor and the items of mastery and control in the second factor (Model 3), a two-factor model containing the items of relaxation and control in the first factor and the items of psychological detachment and mastery in the second factor (Model 4), and a three-factor model including the factor of psychological detachment, the factor of mastery and the combined factor of relaxation and control (Model 5). The factors were allowed to correlate in all multifactorial models. 
As can be seen from the fit indices reported in Table 2, the hypothesized four-factor model (Model 1) provided the best approximation with the given data compared with the other CFA models (Models 2-5). Although the $\chi^{2}$ value of the Model 1 was significant (i.e., an indicator of a poor model fit), all other fit indices were reasonably good. It is a well-known fact that $\chi^{2}$ value tends to increase with large sample sizes (e.g., Raykov, 1998); therefore, it was not considered the most adequate fit index in the present study. A detailed analysis of the modification indices revealed that the relaxation item 2 ("I kick back and relax") showed a cross-loading on the psychological detachment factor. This weakened the goodness of fit of the model but as it was still acceptable we decided to keep our analysis strictly confirmatory and included all items in the model.

As seen from Table 3, the standardized factor loadings were acceptably high in all four factors (ranging from .54 to .91). The highest correlation was found between the relaxation and control factors (.71) and the lowest between the psychological detachment and mastery factors (-.02, $n s)$. Altogether, our Hypothesis 1 expecting four dimensions received support.

TABLE 2

Goodness of fit statistics for the tested CFA models of the Finnish REQ

\begin{tabular}{|c|c|c|c|c|}
\hline Model & $\chi^{2}(d f)$ & RMSEA & $T L I$ & $C F I$ \\
\hline 1. Four-factor model & $364.622(98)$ & .072 & .91 & .93 \\
\hline 2. One-factor model & $3749.235(104)$ & .184 & .42 & .49 \\
\hline $\begin{array}{l}\text { 3. Two-factor model } \\
\text { [(1) detachment and } \\
\text { relaxation and } \\
\text { (2) mastery and control] }\end{array}$ & 1226.678 & .144 & .64 & .69 \\
\hline $\begin{array}{l}\text { 4. Two-factor model } \\
\text { [(1) relaxation and } \\
\text { control and (2) detachment } \\
\text { and mastery] }\end{array}$ & $1321.017(103)$ & .150 & .61 & .66 \\
\hline $\begin{array}{l}\text { 5. Three-factor model } \\
\text { [(1) psychological } \\
\text { detachment, } \\
\text { (2) mastery, and } \\
\text { (3) relaxation } \\
\text { and control] }\end{array}$ & $667.217(101)$ & .104 & .82 & .84 \\
\hline
\end{tabular}

RMSEA = root mean square error of approximation [values .00-.05 indicate a very close model-data fit (Browne \& Cudeck, 1993; Hu \& Bentler, 1998), values .06-.08 a good data-fit, and values .08-.10 a mediocre data-fit (MacCallum, Browne, \& Sugawara, 1996)], TLI = Tucker Lewis Index, CFI = Comparative Fit Index (TLI and CFI values range between 0 and 1 and the values .90 or greater are considered to indicate an acceptable fit of the model; Bollen, 1989; Marsh, Hau, \& Wen, 2004). 
TABLE 3

The four-factor structure of the Finnish REQ

\begin{tabular}{llllll}
\hline & & \multicolumn{4}{c}{ Correlations } \\
\cline { 3 - 5 } Construct and items & Standardized factor loading & $D E$ & $R E$ & $M A$ & $C O$ \\
\hline Detachment (DE) & & & .70 & -.02 & .42 \\
Item 1 & .90 & & & \\
Item 5 & .82 & & & \\
Item 9 & .90 & & .31 & .71 \\
Item 13 & .64 & & & \\
Relaxation (RE) & .74 & & & \\
Item 2 & .75 & & & \\
Item 6 & .75 & & & \\
Item 10 & .74 & & & \\
Item 14 & & & & \\
Mastery (MA) & .70 & & & \\
Item 3 & .78 & & & \\
Item 7 & .70 & & & \\
Item 11 & .79 & & & \\
Item 15 & & & & \\
Control (CO) & .76 & & & \\
Item 4 & .88 & & & \\
Item 8 & .91 & & & \\
Item 12 & .54 & & & \\
Item 16 & & & & & \\
\hline
\end{tabular}

The items are numbered in the same way as in the original measure (Sonnentag \& Fritz, 2007).

\section{Recovery experiences as mediators between job demands and resources and occupational ill-health and well-being}

In investigating recovery experiences as mediators between work characteristics (demands, resources) and occupational ill-health/well-being (fatigue at work, work engagement), we estimated three separate structural equation models (SEM) consecutively by using Mplus 5.2 program (Muthén \& Muthén, 1998-2007) and MLR as the method of estimation. As suggested by Anderson and Gerbing (1988), we first tested a null structural model in which all parameters relating the constructs to one another were fixed at zero (i.e., there are no posited relations of the constructs to one another), and compared it to our hypothesized partial mediation model. For comparison purposes to ensure the validity of the hypothesized partial mediation model, a full mediation model (direct links from job demands and job resources to occupational ill-health and well-being indicators were not estimated) was also tested.

In the models tested, the major study constructs were analysed with latent factors. The four recovery experiences were constructed by the four-factor 
model. Due to the high amount of the observed variables in this study (altogether 57), we could not fully follow the two-step approach suggested by Anderson and Gerbing (1988), that is, to test first the measurement models of all the constructs based on the observed variables (scale items) and, second, include them in the constructed SEM models. Thus, to make the size of the SEM models equitable, we used mainly mean scores of the scales (i.e., the observed sum-variables) in constructing the latent factors. Job demands contained the mean scores of time pressures and demands in decision making, and, in addition, one single question of weekly working hours. Job resources contained the mean scores of job control, social support, and justice of the supervisor. Fatigue at work contained the mean scores of job exhaustion and need for recovery and, in addition, one single item of an individual's own recovery evaluation. Work engagement contained mean scores of vigour, dedication, and absorption.

Before testing the mediation models, we examined the discriminant validity of the four latent constructs of recovery experiences in relation to the latent factors of work characteristics (job resources and demands) and occupational ill-health and well-being (fatigue at work, work engagement). To do this, we constructed altogether 16 one-factor models (e.g., the observed variables of job demands and psychological detachment were set to the same latent factor) and compared them to alternative two-factor models (e.g., the observed variables of job demands and psychological detachment were set to their own factors; factors were allowed to correlate). The 16 chisquare difference tests performed, using the Satorra-Bentler scaled $\chi^{2}$, supported all the two-factor models compared to the corresponding onefactor models. Thus, the constructs turned out to be separate and the further model estimation was justified.

The fit indices of the models (null model, and full and partial mediation models) are reported in Table 4. As seen in the table, the null model was

TABLE 4

The fit indices of the tested SEM models

\begin{tabular}{lcccccc}
\hline & & & & $\begin{array}{c}\text { Model comparison: } \\
\text { Satorra-Bentler } \\
\text { scaled } \Delta \chi^{2}\end{array}$ \\
\hline $\begin{array}{l}\text { SEM models } \\
\text { 1. Null model }\end{array}$ & $1836.278(347)$ & .090 & .77 & .79 & \\
$\begin{array}{l}\text { 2. Full mediation } \\
\text { model }\end{array}$ & $1106.243(326)$ & .067 & .87 & .89 & 1 vs. $2 \Delta \chi^{2}(21)=596.491^{* * *}$ \\
$\begin{array}{l}\text { 3. Partial mediation } \\
\text { model (hypothesized) }\end{array}$ & $964.243(322)$ & .067 & .89 & .91 & 2 vs. $3 \Delta \chi^{2}(4)=283.579^{* * *}$ \\
\hline
\end{tabular}

$* * * P<.001$. 
rejected in relation to the full mediation model which, in turn, was rejected in relation to the hypothesized partial mediation model. Thus, our hypothesized model was supported.

The best-fitting partial mediation model is shown in Figure 2. As can be seen in Figure 2, not all estimated paths were statistically significant in the model ( $t$-values were less than $|1.96|$ for the relationships marked by dotted lines in Figure 2). Of the eight hypothesized partial mediation paths, the model included two indirect effects. First, psychological detachment seemed to mediate the effects of job demands on fatigue: High demands at work were associated with poor psychological detachment from work $(\beta=-.54)$, which, in turn, was associated with a high level of fatigue $(\beta=-.33)$. The direct link from job demands to fatigue at work was nonsignificant. Second, mastery was found to mediate the association between job resources and work engagement: High job resources were associated with high mastery experiences in leisure time $(\beta=.26)$, which were, in turn, associated with a high level of work engagement $(\beta=.22)$ (see Figure 2). The observed mediating effect was partial, as job resources showed a direct association with work engagement; the higher the level of job resources, the higher the level of work engagement.

To assess the statistical significance of these two mediation effects, we used bootstrap method (Mallinckrodt, Abraham, Wei, \& Russell, 2006; Preacher \& Hayes, 2008). We used Mplus program to create 1000 bootstrap samples from the original data in the best-fitting partial mediation structural model (see Figure 2). The 1000 bootstrap samples were run with the biascorrected percentile method to estimate the path coefficients. Point estimates of the magnitude of the indirect effects, that is, the products of the alpha paths (i.e., from work characteristics to recovery experiences) and beta paths (i.e., from recovery experiences to occupational ill-health and well-being), together with the associated 95\% confidence interval (CI) were also estimated through the same 1000 bootstrap samples. If the confidence interval excludes zero, then the indirect effect is considered statistically significant at the 05 level.

The results indicated that the confidence intervals for the two indirect effects in the partial mediation model excluded zero and therefore these two effects were statistically significant $(p<.05)$. First, the mediation of psychological detachment was present in the relationship between job demands and fatigue at work (standardized estimate for specific indirect effect $0.16,95 \% \mathrm{CI}=.030$ to .295 ), and, second, the partial mediation of mastery was present in the relationship between job resources and work engagement (standardized estimate $0.16,95 \% \mathrm{CI}=.016$ to .095 ). Thus, our Hypotheses 2 and 3 got partial support.

Our hypothesized model explained $69 \%$ of the variance in fatigue at work and $39 \%$ of the variance in work engagement. It seemed that job demands 


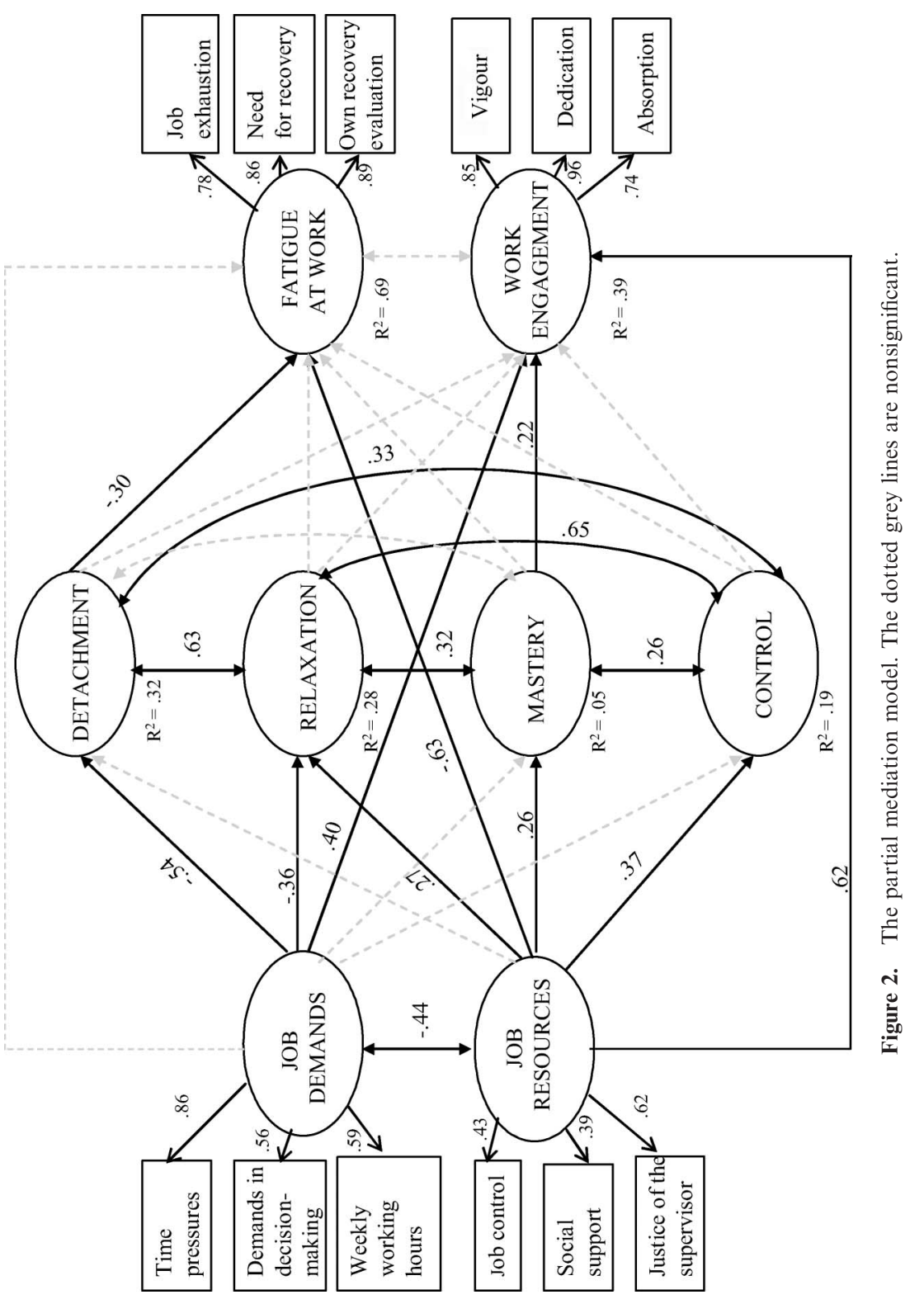


were negatively linked to detachment and relaxation, whereas job resources were positively related to control, mastery, and relaxation. Relaxation and control did not have direct links to either fatigue or work engagement. The link between job resources and fatigue at work was negative and in line with our Hypothesis 4. Contrary to our Hypothesis 5, the direct link between job demands and work engagement was positive; thus, the higher the level of job demands, the higher the level of work engagement.

\section{DISCUSSION}

\section{The mediation role of recovery experiences}

The aim of the present study was to extend the JD-R model by taking into account recovery as an important mediating mechanism between work characteristics and well-being/ill-health. Our study demonstrated, first, that the Finnish REQ measuring the four recovery experiences, psychological detachment, relaxation, mastery, and control during off-job time, turned out to have good construct validity, supporting our Hypothesis 1. Despite that the Finnish REQ might still benefit from some scale development, in particular, this perception concerns the relaxation scale and its Item 2. As a consequence, we concluded that the first prerequisite for sound further analyses of the mediation role of recovery experiences was fulfilled.

Second, our study revealed that recovery-conceptualized as recovery experiences - is a relevant mediating process in the health impairment and motivational processes included in the JD-R model. More specifically, our study revealed two significant mediation paths. First, in the health impairing process, psychological detachment fully mediated the effects of job demands on fatigue at work. Second, in the motivational process, mastery partially mediated the effects of job resources on work engagement. Thus, our Hypotheses 2 and 3 received partial support.

Consequently, of the four recovery experiences, only psychological detachment and mastery functioned as mediators in the work characteristics-well-being/ill-health relationship. High job demands-time pressures, demands in decision making, and long working hours-were linked to poor psychological detachment from work, which in turn was related to high fatigue. Thus, exposure to high job demands was linked to the risk of having difficulties in psychological detachment from work (e.g., Sonnentag \& Bayer, 2005; Sonnentag \& Fritz, 2007). This may occur, for example, through rumination of work-related matters in the evening (see Cropley \& Purvis, 2003). Rumination maintains prolonged cognitive activation, which taxes the same systems activated on the job. This, in turn, maintains fatigue in line with the E-R model (Meijman \& Mulder, 1998). However, relaxation 
did not mediate the link between job demands and fatigue at work. High job demands also challenged relaxation, but the link from relaxation to fatigue at work proved to be nonsignificant. One explanation for this nonexistent link might be the fact that relaxation correlated highly with detachment and control. Therefore, although at the correlational level there were associations between relaxation and fatigue at work, when all recovery experiences were examined simultaneously in the SEM models these direct links disappeared. Another explanation might be that one has to be first able to detach from one's job, before relaxation during leisure time and its positive effects on well-being are possible. Thus, in future we would need longitudinal studies that could better take into account the process nature of recovery. Diary or experience-sampling studies might be best in this regard (Demerouti et al., 2009).

Neither mastery nor control functioned as mediators in the health impairment process. It turned out that job demands did not challenge mastery and control during leisure time. This suggests that job demands did not exhaust an employee's mental and physical resources to the extent that it would jeopardize his or her effort to address new challenges during leisure time or feeling control over nonwork time. Perhaps a higher average level of demands than that prevailing among employees in the present study is needed before this occurs. Our result does not, however, mean that this would have been the case in subgroups of employees.

Generally, in the future we also need studies approaching recovery from a person-oriented approach (i.e., analyses at the subgroup level) instead of the variable-oriented approach (i.e., analyses at the whole sample level) used in the present study (see, e.g., Bergman \& Trost, 2006, for these approaches). Thus, instead of studying recovery experiences as separate variables, it is possible that successful recovery is a result of a certain pattern of recovery experiences. These kinds of patterns can be detected when the individual is the unit of measurement.

Job resources - job control, social support from colleagues, and justice of the supervisor - were linked to mastery experiences, which in turn were related to high work engagement. In addition, job resources were directly linked to work engagement. This partial mediation role of mastery was based on the COR theory (Hobfoll, 1998). Thus, employees who have high resources on the job are likely to have more internal resources (e.g., energy, self-efficacy) available for new challenges and learning, that is, for mastery experiences during nonwork time, and via restoring threatened or creating new resources, these experiences help recover and maintain work engagement.

Thus, our study points to mastery — but not to control during off-job time - as an important mediator in the relationship between job resources and work engagement. High job resources were positively linked to control 
during leisure time, but the link from control to engagement was not significant. Theoretically, it is possible that control over nonwork time is not a sufficient condition to promote work engagement. Its power may be conditional on mastery experiences during leisure time, and therefore only in the case, when control leads to experiences increasing intrinsic motivation work engagement is promoted. This is due to the fact that intrinsic motivation plays a central role in work engagement. Another explanation is related to the fact that at the correlational level the positive link from control to the core dimensions of work engagement (vigour and dedication) seemed to exist, but there was no link to the third dimension (absorption). This lacking link may be behind the obtained SEM results.

Contrary to our expectations, psychological detachment or relaxation did not partially mediate the link between job resources and work engagement. There was no link from job resources to detachment, although job resources seemed to promote relaxation during off-job time. This may be related to the fact that high job resources may increase the person's positive thoughts about his or her job during leisure time. Therefore, psychological detachment does not occur. Positive thoughts may, however, promote relaxation through positive affect (see, e.g., Sonnentag \& Fritz, 2007). The missing link from psychological detachment and relaxation to work engagement might be related to the role of absorption in work engagement. At the correlational level, psychological detachment was negatively associated with absorption, whereas relaxation had no link to it. Thus, absorption behaved differently (i.e., the less detachment, the more absorption) compared to vigour, which was positively associated with psychological detachment and relaxation (i.e., the less detachment and relaxation, the less vigour).

Moreover, lack of job resources contributed to fatigue at work in line with our Hypothesis 4 (see, e.g., Hakanen et al., 2008; Schaufeli \& Bakker, 2004). Job demands showed, however, a direct positive link to work engagement, contrary to our Hypothesis 5 expecting a negative link. We based our hypothesis on the fact that the majority of studies have supported a negative link (see Halbesleben, 2010). However, some cross-sectional studies have revealed that job demands may have a positive link to work engagement (Kinnunen et al., 2008; Schaufeli et al., 2008). As Schaufeli and colleagues (2008) have formulated, this may indicate that engaged individuals work long hours in demanding jobs - and do not necessarily perceive long working hours as stressful. This observed link may also be related to the samples studied. Our sample was well-educated $(60 \%$ had a university degree) as was also the case in the studies conducted among managers by Kinnunen et al. (2008) and Schaufeli et al. (2008). Altogether, these findings give evidence for intertwining effects between the motivational and health impairment processes. They also imply that the role of job 
demands in relation to work engagement deserves more attention in the future.

\section{Limitations}

This study is not without limitations. First, all of the data were based on self-reports, which means that the magnitude of the effects reported may be biased due to common method variance. However, there are studies (e.g., Semmer, Zapf, \& Greif, 1996) indicating that common method variance is not as troublesome as one might expect in studies like this. In addition, we were able to show that our main constructs were separate from each other. Nevertheless, future research could benefit from including more objectively measured variables such as supervisor or expert ratings for work characteristics and physiological markers as indicators of health.

Another limitation is the cross-sectional nature of our study that prevents us from drawing causal conclusions. For example, regarding recovery experiences, our results may indicate that poor detachment from work impairs occupational well-being, but it could also be that employees suffering from impaired occupational well-being cannot detach from their work. This issue of causality can only be solved by using a longitudinal design. However, earlier longitudinal studies have either not shown reversed associations between job demands and resources and burnout and engagement (Hakanen et al., 2008) or they have been weaker than the normal causal associations between job resources and work engagement (de Lange, de Witte, \& Notelaers, 2008).

A further limitation derives from the relatively low response rate of the study $(51 \%)$. However, the response rate is higher than that (35.7\%) typical of studies conducted in organizations (see Baruch \& Holtom, 2008, for a meta-analysis). In addition, the respondents represented the original sample in terms of gender (the only background information available) reasonably well, and the fact that the sample was heterogeneous adds to the generalizability of the findings. Despite that, our findings should be replicated in other samples. It is also good to notice that our sample consisted of employees in five organizations; therefore, our participants were nested within organization. However, due to the low number of organizations and a lack of information about work units, we were not able to take this into account and conduct multilevel analyses. Generally, ignoring the nested nature of the sample may yield more significant associations between the variables (e.g., Goldstein, 2002). Finally, it is worth noticing that some of our measures suffered from either low reliability (demands in decision making) or were single-item measures (e.g., own recovery evaluation) of which reliability cannot be evaluated. 


\section{CONCLUSION}

Our study has implications for both the JD-R model and its applications. First, with regard to the model, our study suggests that it is important to consider recovery as a mediating mechanism between work characteristics and ill-health/well-being. Of the recovery experiences, psychological detachment functioned as a mediator in the health impairment process, and mastery in the motivational process. Therefore, we would like to encourage researchers in the future to further test our Job DemandsResources-Recovery model (JD-R-R model). In particular, longitudinal research - including diary studies - using samples of employees in various types of jobs are needed.

In terms of practical implications, our results suggest that, besides work characteristics, the personal strategies by which individuals try to restore their energy resources are also important for reducing fatigue at work and increasing work engagement. The Finnish REQ proved to be a valid measure to assess these personal recovery strategies for both research and practical purposes. As psychological detachment from work proved significant with regard to decreased fatigue, we encourage employees to detach from their jobs during afterwork hours. One way to enhance psychological detachment is to keep one's work life separate from one's nonwork life (see also Sonnentag, Mojza, et al., 2008). In order that employees can be successful in this segmentation, organizations should address the implicit norms of unlimited availability, especially prevalent in upper white-collar jobs. More concretely, this means questioning the necessity of long-working-hours culture. In addition, it seems essential for building work engagement to increase the rewarding aspects of work, which also seem to promote mastery experiences during afterwork hours, that is, to start gain spirals.

\section{REFERENCES}

Anderson, J. C., \& Gerbing, D. W. (1988). Structural equation modeling in practice: A review and recommended two-step approach. Psychological Bulletin, 103, 411-423.

Bakker, A., Hakanen, J., Demerouti, E., \& Xanthopoulou, D. (2007). Job resources boost work engagement, particularly when job demands are high. Journal of Educational Psychology, 99, 274-284.

Bakker, A. B., \& Demerouti, E. (2007). The Job Demands-Resources Model: State of the art. Journal of Managerial Psychology, 22, 309-328.

Bakker, A. B., Schaufeli, W. B., Leiter, M., \& Taris, T. (2008). Work engagement: An emerging concept in occupational health psychology (Position paper). Work and Stress, 22, 187-200.

Bandura, A. (1997). Self-efficacy: The exercise of control. New York, NY: Freeman.

Baruch, Y., \& Holtom, B. (2008). Survey response rate levels and trends in organizational research. Human Relations, 61, 1139-1160.

Bergman, L., \& Trost, K. (2006). The person-oriented vs. variable-oriented approach: Are they complementary, opposite, or exploring different worlds? Merrill-Palmer Quarterly, 52, 601-632. 
Binnewies, C., Sonnentag, S., \& Mojza, E. (2009). Feeling recovered and thinking about the good sides of one's work. Journal of Occupational Health Psychology, 14, 243-256.

Bollen, K. A. (1989). Structural equations with latent variables. New York, NY: Wiley.

Browne, M. W., \& Cudeck, R. (1993). Alternative ways of assessing model fit. In K. A. Bollen \& J. S. Long (Eds.), Testing structural equation models (pp. 136-162). Newbury Park, CA: Sage.

Craig, A., \& Cooper, R. E. (1992). Symptoms of acute and chronic fatigue. In A. P. Smith \& D. M. Jones (Eds.), Handbook of human performance: Vol. 3. State and trait (pp. 289-339). San Diego, CA: Academic Press.

Cropley, M., \& Purvis, L. (2003). Job strain and rumination about work issues during leisure time: A diary study. European Journal of Work and Organizational Psychology, 12, 195-207.

De Croon, E. M., Sluiter, J. K., Blonk, R. W. B., Broersen, J. P. J., \& Frings-Dresen, M. H. W. (2004). Stressful work, psychological strain, and turnover: A 2-year prospective cohort of truck drivers. Journal of Applied Psychology, 89, 442-454.

De Lange, A., de Witte, H., \& Notelaers, G. (2008). Should I stay or should I go? Examining longitudinal relations among job resources and work engagement for stayers versus movers. Work and Stress, 22, 201-223.

Demerouti, E., Bakker, A. B., Geurts, S. A., \& Taris, T. W. (2009). Daily recovery from workrelated effort during non-work time. In S. Sonnentag, P. Perrewe, \& D. Ganster (Eds.), Current perspectives on job-stress recovery (pp. 85-123). Bingley, UK: Emerald.

Demerouti, E., Bakker, A. B., Nachreiner, F., \& Schaufeli, W. B. (2001). The job demandsresources model of burnout. Journal of Applied Psychology, 86, 499-512.

De Raeve, L., Vasse, R., Jansen, N., van der Brandt, P., \& Kant, I. (2007). Mental health effects of changes in psychosocial work characteristics: A prospective cohort study. Journal of Occupational Environmental Medicine, 49, 890-899.

Fritz, C., \& Sonnentag, S. (2005). Recovery, health, and job performance: Effects of weekend experiences. Journal of Occupational Health Psychology, 10, 187-199.

Fritz, C., \& Sonnentag, S. (2006). Recovery, well-being, and performance-related outcomes: The role of workload and vacation experiences. Journal of Applied Psychology, 91, 936-945.

Geurts, S. A. E., \& Sonnentag, S. (2006). Recovery as an explanatory mechanism in the relation between acute stress reactions and chronic health impairment. Scandinavian Journal of Work, Environment and Health, 32, 482-492.

Goldstein, H. (2002). Multilevel statistical models. London, UK: Edward Arnold.

Grebner, S., Semmer, N., \& Elfering, A. (2005). Working conditions and three types of wellbeing: A longitudinal study with self-report and rating data. Journal of Occupational Health Psychology, 10, 31-43.

Hakanen, J., Bakker, A., \& Schaufeli, W. B. (2006). Burnout and engagement among teachers. Journal of School Psychology, 43, 495-513.

Hakanen, J., Schaufeli, W. B., \& Ahola, K. (2008). The Job Demands-Resources Model: A three-year cross-lagged study of burnout, depression, commitment, and work engagement. Work and Stress, 22, 224-241.

Halbesleben, J. R., \& Buckley, M. R. (2004). Burnout in organizational life. Journal of Management, 30, 859-879.

Halbesleben, J. R. B. (2010). A meta-analysis of work engagement: Relationships with burnout, demands, resources, and consequences. In A. B. Bakker \& M. P. Leiter (Eds.), Work engagement: Recent developments in theory and research (pp. 102-117). New York, NY: Psychology Press.

Hobfoll, S. E. (1998). Stress, culture, and community: The psychology and physiology of stress. New York, NY: Plenum Press.

Hobfoll, S. E., Johnson, R. J., Ennis, N., \& Jackson, A. P. (2003). Resource loss, resource gain, and emotional outcomes among inner city women. Journal of Personality and Social Psychology, 84, 632-643. 


\section{KINNUNEN ET AL.}

Hu, L., \& Bentler, P. M. (1998). Fit indices in covariance structure modeling: Sensitivity to underparameterized model misspecification. Psychological Methods, 3, 424-453.

Jansen, N. W. H., Kant, I. J., van Amelsvoort, L., Nijhuis, F., \& van den Brandt, P. A. (2003). Need for recovery from work: Evaluating short-term effects of working hours, patterns and schedules. Ergonomics, 46, 664-680.

Jansen, N. W. H., Kant, I. J., \& van den Brandt, P. A. (2002). Need for recovery in the working population: Description and associations with fatigue and psychological distress. International Journal of Behavioral Medicine, 9, 322-340.

Kalimo, R., Hakanen, J., \& Toppinen-Tanner, S. (2006). Maslachin yleinen työuupumuksen arviointimenetelmä MBI-GS [The Finnish version of Maslach's Burnout Inventory-General Survey]. Helsinki, Finland: Työterveyslaitos.

Kinnunen, U., Feldt, T., \& Mäkikangas, A. (2008). Testing the effort-reward imbalance model among Finnish managers: The role of perceived organizational support. Journal of Occupational Health Psychology, 13, 114-127.

Lee, R. T., \& Ashforth, B. E. (1996). A meta-analytic examination of the correlates of the three dimensions of job burnout. Journal of Applied Psychology, 81, 123-133.

Lindström, K., Elo, A.-L., Skogstad, A., Dallner, M., Gamberale, F., Hottinen, V., et al. (2000). User's guide for the QPSNordic: General Nordic questionnaire for psychological and social factors at work. Copenhagen, Denmark: Nordic Council of Ministers.

MacCallum, R. C., Browne, M. W., \& Sugawara, H. M. (1996). Power analysis and determination of sample size for covariance structure modeling. Psychological Methods, 1 , $130-149$.

Mallinckrodt, B., Abraham, W. T., Wei, M., \& Russell, D. W. (2006). Advances in testing the statistical significance of mediation effects. Journal of Counseling Psychology, 53, 372378.

Marsh, H. W., Hau, K., \& Wen, Z. (2004). In search of golden rules: Comment in hypothesis testing approaches to setting cutoff values for fit indexes and dangers in over-generalizing $\mathrm{Hu}$ and Bentler's (1999) findings. Structural Equation Modeling, 11, $320-341$.

Maslach, C., Jackson, S. E., \& Leiter, M. P. (1996). Maslach Burnout Inventory manual (3rd ed.). Palo Alto, CA: Consulting Psychologists Press.

Maslach, C., Schaufeli, W. B., \& Leiter, M. P. (2001). Job burnout. Annual Review of Psychology, 52, 397-422.

Mauno, S., Kinnunen, U., \& Ruokolainen, M. (2007). Job demands and resources as antecedents of work engagement: A longitudinal study. Journal of Vocational Behavior, 70, $149-171$.

Meijman, T. F., \& Mulder, G. (1998). Psychological aspects of workload. In P. J. D. Drenth \& H. Thierry (Eds.), Handbook of work and organizational psychology: Vol. 2. Work psychology (pp. 5-33). Hove, UK: Psychology Press.

Moreno-Jimenez, B., Mayo, M., Sanz-Vergel, A. I., Geurts, S., Rodriguez-Munoz, A., \& Garrosa, E. (2009). Effects of work-family conflict on employees' well-being: The moderating role of recovery strategies. Journal of Occupational Health Psychology, 14, $427-440$.

Muthén, L. K., \& Muthén, B. O. (1998-2007). Mplus user's guide (5th ed.). Los Angeles, CA: Muthén \& Muthén.

Mäkikangas, A., \& Kinnunen, U. (2003). Psychosocial work stressors and well-being: Selfesteem and optimism as moderators in a one-year longitudinal sample. Personality and Individual Differences, 35, 537-557.

Preacher, K., \& Hayes, A. (2008). Asymptotic and re-sampling strategies for assessing and comparing indirect effects in multiple mediator models. Behavioral Research Methods, 40, 879-891. 
Rau, R. (2006). Learning opportunities at work as a predictor for recovery and health. European Journal of Work and Organizational Psychology, 15, 181-196.

Raykov, T. (1998). On the use of confirmatory factor analysis in personality research. Personality and Individual Differences, 24, 291-293.

Schaufeli, W., Taris, T., \& van Rhenen, W. (2008). Workaholism, burnout, and work engagement: Three of a kind or three different kinds of employee well-being? Applied Psychology: An International Review, 57, 173-203.

Schaufeli, W. B., \& Bakker, A. B. (2004). Job demands, job resources, and their relationship with burnout and engagement. Journal of Organizational Behavior, 25, 293-315.

Schaufeli, W. B., Bakker, A. B., \& Salanova, M. (2006). The measurement of work engagement with a short questionnaire: A cross-national study. Educational and Psychological Measurement, 66, 701-716.

Schaufeli, W. B., \& Enzmann, D. (1998). The burnout companion to study and practice: A critical analysis. Washington, DC: Taylor \& Francis.

Schaufeli, W. B., Salanova, M., González-Romá, V., \& Bakker, A. B. (2002). The measurement of engagement and burnout: A two sample confirmatory factor analytic approach. Journal of Happiness Studies, 3, 71-92.

Semmer, N., Zapf, D., \& Greif, S. (1996). "Shared job strain": A new approach for assessing the validity of job stress measurements. Journal of Occupational and Organizational Psychology, 69, 293-310.

Seppälä, P., Mauno, S., Feldt, T., Hakanen, J., Kinnunen, U., Tolvanen, A., \& Schaufeli, W. (2009). The construct validity of the Utrecht Work Engagement Scale: Multi-sample and longitudinal evidence. Journal of Happiness Studies, 10, 459-481.

Siltaloppi, M., Kinnunen, U., \& Feldt, T. (2009). Recovery experiences as moderators between psychosocial work characteristics and occupational well-being. Work and Stress, 23, 330348.

Sluiter, J. K., van der Beek, A. J., \& Frings-Dresen, M. H. W. (1999). The influence of work characteristics on the need for recovery and experienced health: A study on coach drivers. Ergonomics, 42, 573-583.

Sonnentag, S., \& Bayer, U.-V. (2005). Switching off mentally: Predictors and consequences of psychological detachment from work during off-job time. Journal of Occupational Health Psychology, 10, 393-414.

Sonnentag, S., Binnewies, C., \& Mojza, E. (2008). Did you have a nice evening? A day-level study of recovery experiences, sleep, and affect. Journal of Applied Psychology, 93, 674-684.

Sonnentag, S., \& Fritz, C. (2007). The Recovery Experience Questionnaire: Development and validation of a measure for assessing recuperation and unwinding from work. Journal of Occupational Health Psychology, 12, 204-221.

Sonnentag, S., Kuttler, I., \& Fritz, C. (2010). Job stressors, emotional exhaustion, and need for recovery: A multi-source study on the benefits of psychological detachment. Journal of Vocational Behavior, 76, 355-365.

Sonnentag, S., Mojza, E. J., Binnewies, C., \& Scholl, A. (2008). Being engaged at work and detached at home: A week-level study on work engagement, psychological detachment, and affect. Work and Stress, 22, 257-276.

Sonnentag, S., \& Zijlstra, F. R. H. (2006). Job characteristics and off-job activities as predictors of need for recovery, well-being, and fatigue. Journal of Applied Psychology, 91, 330-350.

Trougakos, J. P., \& Hideg, I. (2009). Momentary work recovery: The role of within-day work breaks. In S. Sonnentag, P. L. Perrewé, \& D. C. Ganster (Eds.), Current perspectives on jobstress recovery (pp. 37-84). Bingley, UK: Emerald.

Van den Broeck, A., Vansteenkiste, M., de Witte, H., \& Lens, W. (2008). Explaining the relationships between job characteristics, burnout and engagement: The role of basic psychological need satisfaction. Work and Stress, 22, 277-294. 


\section{KINNUNEN ET AL.}

Van Veldhoven, M., \& Broersen, S. (2003). Measurement quality and validity of the need for recovery scale. Occupational and Environmental Medicine, 60, i3-i9.

Xanthopoulou, D., Bakker, A., Demerouti, E., \& Schaufeli, W. B. (2007). The role of personal resources in the job demands-resources model. International Journal of Stress Management, 14, 121-141.

Original manuscript received January 2010

Revised manuscript received August 2010

First published online September 2011 